\title{
Be Aware, Be Alert, Be Prepared: Endoscopy during the COVID-2019 Pandemic
}

\author{
Manu Tandan ${ }^{1} \quad$ Nitin Jagtap ${ }^{1}$ \\ ${ }^{1}$ Department of Gastroenterology, Asian Institute of \\ Gastroenterology, Hyderabad, India
}

J Digest Endosc 2020;11:59-60

These are unexpected and uncertain times. The world is at war with an unseen enemy that respects no borders or ethnicity. As medical personnel doctors and health care workers (HCW) are at the forefront of this battle, we need to be well prepared. Gastroenterologists and more specifically endoscopists will come across a daily quota of patients with emergencies such as gastrointestinal (GI) bleed, obstructive jaundice, and cholangitis. Emergency endoscopy in such patients is often life saving. In this issue, Dr. P. Zachariah has clearly explained the way to go ahead with GI endoscopy during this pandemic. ${ }^{1}$ Our own societies (Indian Society of Gastroenterology, Society of Gastrointestinal Endoscopy of India, and Indian National Association for Study of the Liver) have also put forward guidelines for proper conduct of the procedures. ${ }^{2}$ Many other societies, especially from countries which are effected by the virus, have also advocated similar procedural guidelines and it would be worthwhile for all endoscopists to familiarize ourselves with the same. ${ }^{3-5} \mathrm{~A}$ critical review of this article based on evidence is not feasible as no unit or center has sufficient experience of the same. It is up to each endoscopy unit to adopt to these guidelines and suggestions as well as those described in detail in the article by Dr. P. Zachariah.

From our own experience as a tertiary large volume referral center with a high turnover of therapeutic endoscopic procedures, we would like to share our approach to endoscopy during the COVID-19 pandemic. We propose a timeline for endoscopic procedures to return to normalcy during and after pandemic (- Fig. 1).

Proper selection of the patient prior to the procedure is essential. As the total number of patients have reduced, a resident can be assigned for the preprocedural checkup with emphasis on COVID 19-related symptoms and contact and travel history. All elective procedures should be deferred. ${ }^{6}$ Emergencies should be triaged. ${ }^{2,3}$ Low-risk patients are those who have no symptoms of flu, no travel history, or a contact with a COVID-19 positive patient. Intermediate risk is considered if a patient has one or more of the above. A high-risk patient is one who has been tested COVID-19 positive. The levels of personal protection for the endoscopists and support staff ideally should be complete in all cases. ${ }^{7}$ However,
Address for correspondence Manu Tandan, MD, DM, Department of Gastroenterology, Asian Institute of Gastroenterology, Hyderabad 500082, India (e-mail: mantan_05@rediffmail.com).

practical issue of availability and costs are often a limitation. A high or an intermediate risk patient, however, must be endoscoped with complete protection as outlined in the article. In case these personal protection kits are in limited supply, low-risk patients can be endoscoped using a gown, cap, mask, and a self-made plastic face cover and goggles. It is ideal to delegate a single endoscopist for the entire day so that the limited resources can be utilized better. As the number of patients is bound to be limited the procedural load is unlikely to be daunting for a single endoscopist. Dr. P. Zachariah has detailed the care that should be taken during the procedure as well as shown a flow chart for the management of the endoscopy unit. High-risk HCWs should avoid performing these procedures, especially those with age $>65$ years, diabetes mellitus, and preexisting cardiopulmonary diseases. It is advisable to use conscious sedation in all patients because of minimizing restlessness, gagging, and coughing-all of which can contribute to aerosol spread. ${ }^{6}$ The number of endoscopy and anesthetists assistants present in the endoscopy room should be minimized. ${ }^{8}$ Postprocedure cleaning of the scope, endoscopy table, and surroundings have been detailed well in the article.

In view of the precautions and the extra care as well as personal protection required during endoscopy procedures, it is advisable that outpatient clinics with a single endoscopist should not perform procedures during this pandemic. All patients are ideally taken care by large and tertiary setups with multiple endoscopists, resources, anesthetists, support staff, and facilities for hospitalization and intensive care.

In spite of all the precautions mentioned in the various guidelines, limitations are bound to be present. As mentioned earlier, resources such as personal protection may not be available and the cost of using disposables could be a hindrance. Further asymptomatic patient may be placed in a low-risk group yet be a potential danger to HCWs and endoscopists.

However, the pandemic is here. Emergencies requiring life-saving endoscopic procedures will always be seen. So, be alert, be aware, and be prepared for this situation and hope for the best outcome.

Take care.
DOI https://doi.org/ 10.1055/s-0040-1712704 ISSN 0976-5042.
(C)2020 Society of Gastrointestinal Endoscopy of India
License terms

(요 (1) $\odot \circledast$ 


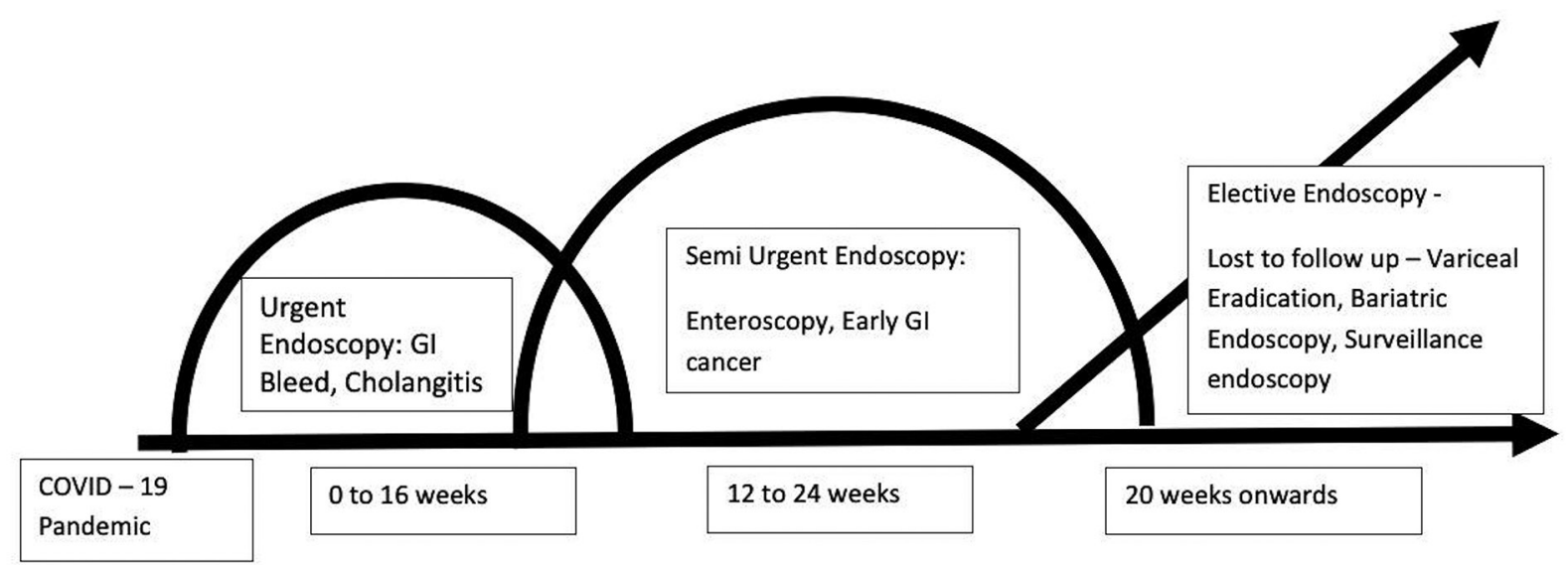

Fig. 1 Proposed time line for endoscopy in coronavirus disease 2019 pandemic.

\section{Authors' Contributions}

M.T. has designed the draft of manuscript. N.J. and M.T. reviewed literature, prepared manuscript, and approved final manuscript.

\section{Conflict of Interest}

None declared.

\section{Funding}

None.

\section{References}

1 Zacharias P, Techniques of GI Endoscopy: Do We Need to Change Anything? J Digest Endoscopy 2020;11;55-58

2 PhilipM, LakhtakiaS, AggarwalR, et al. Joint Guidance from the Society of Gastrointestinal Endoscopy of India (SGEI), Indian Society of Gastroenterology (ISG), and Indian National Association for Study of the Liver(INASL) for Gastroenterologists and Gastrointestinal Endoscopists on the Prevention, Care, and Management of Patients with COVID-19. J Digest Endoscopy 2020 Available at: https://www.thieme-connect. com/products/ejournals/pdf/10.1055/s-0040-1709837.pdf Accessed April 29, 2020

3 Chiu PWY, Ng SC, Inoue H, et al. Practice of endoscopy during COVID-19 pandemic: position statements of the Asian Pacific Society for Digestive Endoscopy (APSDE-COVID statements). Gut 2020 gutjnl-2020-32118510.1136/gutjnl-2020-321185

4 Han J, Kim EY. Sharing our experience of operating an endoscopy unit in the Midst of a COVID-19 outbreak. Clin Endosc 2020;53(2):243-245

5 Gralnek IM, Hassan C, Beilenhoff U, et al. ESGE and ESGENA position statement on gastrointestinal endoscopy and the COVID-19 pandemic. Endoscopy 2020;10.1055/a-1155-6229

6 Repici A, Pace F, Gabbiadini R, et al; ITALIAN GI-COVID19 Working Group. Endoscopy units and the COVID-19 outbreak: a multi-center experience from Italy. Gastroenterology 2020;S0016-5085(20)30466-210.1053/j.gastro.2020.04.003

7 Thompson CC, Shen L, Lee LS. COVID-19 in endoscopy: time to do more? Gastrointest Endosc 2020;S0016-5107(20)34126-2 10.1016/j.gie.2020.03.3848

8 Soetikno R, Teoh AY, Kaltenbach T, et al. Considerations in performing endoscopy during the COVID-19 pandemic. Gastrointest Endosc 2020;S0016-5107(20)34033-510.1016/j. gie.2020;11;55-58 